Atmos. Chem. Phys., 10, 2813-2824, 2010

www.atmos-chem-phys.net/10/2813/2010/

(c) Author(s) 2010. This work is distributed under

the Creative Commons Attribution 3.0 License.

\title{
On retrieval of lidar extinction profiles using Two-Stream and Raman techniques
}

\author{
I. S. Stachlewska ${ }^{1,2}$ and C. Ritter ${ }^{1}$ \\ ${ }^{1}$ Alfred Wegener Institute for Polar and Marine Research, Telegrafenberg A43, 14473 Potsdam, Germany \\ ${ }^{2}$ Institute of Geophysics, Faculty of Physics, University of Warsaw, Pasteura 7, 02-093 Warsaw, Poland \\ Received: 8 July 2009 - Published in Atmos. Chem. Phys. Discuss.: 28 September 2009 \\ Revised: 15 February 2010 - Accepted: 15 March 2010 - Published: 25 March 2010
}

\begin{abstract}
The Two-Stream technique employs simultaneous measurements performed by two elastic backscatter lidars pointing at each other to sample into the same atmosphere. It allows for a direct retrieval of the extinction coefficient profile from the ratio of the two involved lidar signals. During a number of Alfred-Wegener-Institute (AWI) campaigns dedicated to Arctic research, the AWI's Polar 2 aircraft with the integrated onboard nadir-pointing Airborne Mobile Aerosol Lidar (AMALi) was utilised. The aircraft flew over a vicinity of Ny Ålesund on Svalbard, where the zenith-pointing Koldewey Aerosol Raman Lidar (KARL) has been located. This experimental approach gave the unique opportunity to retrieve the extinction profiles with a rarely used Two-Stream technique against a well established Raman technique. Both methods were applied to data obtained for clean Arctic conditions during the Arctic Study of Tropospheric clouds and Radiation (ASTAR 2004) campaign, and slightly polluted Arctic conditions during the Svalbard Experiment (SvalEx 2005) campaign. Successful comparison of both evaluation tools in different measurement conditions demonstrates sensitivity and feasibility of the Two-Stream method to obtain particle extinction and backscatter coefficients profiles without assumption of their relationship (lidar ratio). The method has the potential to serve as an extinction retrieval tool for KARL or AMALi simultaneous observations with the space borne CALIPSO lidar overpasses during the ASTAR 2007.
\end{abstract}

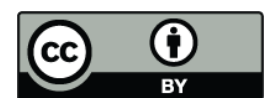

Correspondence to: I. S. Stachlewska (iwona.stachlewska@igf.fuw.edu.pl)

\section{Introduction}

Retrieval of the particle microphysical parameters (particle effective radius, index of refraction and size distribution), from lidar derived optical properties of particles in the atmosphere (particle extinction and backscatter coefficient profiles) consists of a mathematically ill-posed inversion problem (Böckmann, 2001). The emergent efficiencies, typically taken from the Mie theory, act differently for extinction and backscatter coefficients. Hence, any inversion of microphysical parameters fed with both coefficients calculated independently is performed more precisely, especially for the determination of the particle size distribution (Müller et al., 1999; Veselovskii et al., 2002; Böckmann and Kirsche, 2006). Obtaining information on the particle extinction $\alpha^{\text {part }}(h)$ and backscatter $\beta^{\text {part }}(h)$ coefficients without the often used assumption of their relationship signifies a great step forward in the interpretation of lidar data. Unfortunately, the commonly used elastic backscatter lidar cannot alone provide complete information for the inversion of the microphysical parameters (two unknown coefficients in one equation describing a lidar return signal, Eq. 1). The standard Klett-FernaldSasano approach for the evaluation of elastic backscatter lidar data (Klett, 1981, 1985; Fernald, 1984; Sasano, 1985) requires knowledge or an assumption of the backscatter coefficient calibration value $\beta_{\text {ref }}$ and the lidar ratio $B(h)=\frac{\alpha^{\text {part }}(h)}{\beta^{\text {part }}(h)}$. The latter is usually not a very well known atmospheric property, as it varies significantly with the chemical composition and size distribution of the aerosol particles present in the atmosphere (Ackermann, 1998).

If the elastic backscatter lidar is additionally equipped with the Raman-shifted detection channels then an independently obtained extinction profile can be contributed towards

Published by Copernicus Publications on behalf of the European Geosciences Union. 
analytical solution for the retrieval (Ansmann et al., 1990, 1992). The cross-section for the inelastic Raman scattering of laser light with matter is almost three orders of magnitude lower than the cross-section for the elastic Rayleigh/Mie scattering. This results in significantly noise polluted signals obtained from the Raman channels. The Raman signals are usually strongly averaged in time and range for further analyses, which can severely influence the results of the Raman extinction coefficient retrieval (Pornsawad, 2008).

There is another raerly applied approach, which provides independent information to the classic solution of the lidar problem. The Two-Stream inversion, also referred to as the bipath or the double-ended lidar technique, requires two elastic backscatter lidars pointing at each other. This method was introduced in the 1980s (Kunz, 1987; Hughes and Paulson, 1988), and later revised for application to ground based lidars pointing at each other horizontally (Jörgensen et al., 1997); zenith-pointing ground based lidar and nadir-pointing airborne lidar (Stachlewska et al., 2005; Ritter et al., 2006) and also discussed for zenith-pointing ground based lidar and nadir-pointing space borne lidar (Cuesta and Flamant, 2004; Wang et al., 2007). The Two-Stream technique allows for the direct retrieval of a range/height dependent extinction coefficient with the only assumption being that the atmosphere, sampled from opposite directions by the two lidars, is the same. With this method the backscatter coefficient can also be obtained if any of the employed lidar instrumental constants $C$ or a backscatter reference value $\beta_{\text {ref }}$ at any given height in the interval covered by lidars' simultaneous observations is known.

In this paper we present a study dedicated to the direct comparison of the Two-Stream particle extinction and backscatter coefficient profiles, and the lidar ratio profiles with the respective Raman retrievals. The Two-Stream method was applied to data recorded during simultaneous measurements taken with the nadir-pointing Airborne Mobile Aerosol Lidar (AMALi), integrated onboard the AWI research aircraft Polar 2. The aircraft flew over the zenithpointing Koldewey Aerosol Raman Lidar (KARL) based in Ny Ålesund on Svalbard. Both lidars and their configurations during the measurements are discussed in Appendices A and B. The Two-Stream $\beta_{\mathrm{TS}}^{\text {part }}(h), \alpha_{\mathrm{TS}}^{\text {part }}(h)$ and $B_{\mathrm{TS}}(h)$ profiles obtained on 15 May 2004 and 19 May 2004 during the the Arctic Study of Tropospheric clouds and Radiation (ASTAR) campaign and on 14 April 2005 during the Svalbard Experiment (SvalEx) campaign are discussed. On each of these days the KARL performed inelastic Raman and elastic backscatter measurements for which the Raman $\alpha_{\mathrm{RM}}^{\mathrm{part}}(h)$, $\beta_{\mathrm{RM}}^{\text {part }}(h)$ and $B_{\mathrm{RM}}(h)$ were retrieved. Good agreement of the results obtained with the two evaluation techniques proves the feasibility of the Two-Stream methodology for the application to the nadir-pointing, low altitude, airborne lidar measurements.
In the future we plan to evaluate the data collected during the ASTAR 2007 by the zenith-pointing airborne AMALi and the satellite CALIPSO lidar (Winker et al., 2007) to perform a feasibility study of this configuration.

\section{Theoretical background}

In the situation presented here the measuring scheme consisted of a zenith-pointing ground based lidar (denoted "K"), flown over at a height $h_{\mathrm{f}}$ by a nadir-pointing airborne lidar (denoted "A"). Assuming that the same air column was probed when the airborne lidar overflew the ground based lidar, both systems perceived this same air differently; the ground based system with density decreasing with height and vice versa for the airborne instrument. This ensured mathematically independent information content in both lidar equations. The elastic lidar equation (Kovalev and Eichinger, 2004) describes the received signal as a function of the atmospheric and system parameters. Assumptions of quasimonochromatic coherent emitted laser light and instantaneous elastic or inelastic scattering are taken into account, while processes of multiple scattering of light are neglected (discussed later). The lidar equation is usually used in a form of the range corrected signal $S(h)$, obtained by multiplication of the detected signal with the squared range vector. The ground based lidar equation can be written as in Eq. (1) and the airborne lidar equation as in Eq. (2).

$$
\begin{aligned}
& S_{\mathrm{K}}(h)=P_{\mathrm{K}}(h) h^{2}=C_{\mathrm{K}} \beta(h) T_{[0, h]}^{2}(h) \\
& S_{\mathrm{A}}(h)=P_{\mathrm{A}}(h)\left(h_{\mathrm{f}}-h\right)^{2}=C_{\mathrm{A}} \beta(h) T_{\left[h_{\mathrm{f}}, h\right]}^{2}(h)
\end{aligned}
$$

The $h$ denotes the distance between lidar and target particles or molecules. The $P(h)$ denotes then the intensity of the detected backscattered signal at a time $t=2 \mathrm{~h} / \mathrm{c}$, with $c$ being the speed of light. The $C$ is the lidar instrumental constant. The $\beta(h)=\beta^{\text {mol }}(h)+\beta^{\text {part }}(h)$ is the total backscatter coefficient, due to molecules and particles present at the height $h$. The last term $T$ describes the atmospheric transmittance (Eq. 3) between the ground based or airborne lidar and the height $h$.

$$
T(h, \lambda)=\exp \left(-\int_{h_{0}}^{h} \alpha(\tilde{h}, \lambda) d \tilde{h}\right)
$$

The $\alpha(h)=\alpha_{\text {scat }}^{\mathrm{mol}}(h)+\alpha_{\mathrm{scat}}^{\mathrm{part}}(h)+\alpha_{\mathrm{abs}}^{\mathrm{mol}}(h)+\alpha_{\mathrm{abs}}^{\mathrm{part}}(h)$ is the total extinction coefficient dependent on the total number of molecules and particles scattering and/or absorbing the laser light at the height $h$.

In the Two-Stream approach the simultaneous equation system has four unknowns (two unknown lidar instrumental constants $C_{\mathrm{K}}$ and $C_{\mathrm{A}}$ and unknown $\alpha$ and $\beta$ coefficients). By dividing Eq. (2) by Eq. (1) the backscatter coefficient terms are eliminated and an expression for the height dependent extinction coefficient can be calculated (Eq. 4). Obtained this 
way, $\alpha_{\mathrm{TS}}(h)$ does not require any a priori assumption or further calibration and normalisation.

$$
\alpha_{\mathrm{TS}}(h)=\frac{1}{4} \cdot \frac{d}{d h}\left(\ln \left(\frac{S_{\mathrm{A}}(h)}{S_{\mathrm{K}}(h)}\right)\right)
$$

After the retrieval of the extinction coefficient, the atmospheric transmittance can be obtained, and hence the ratio between both lidar instrumental constants $\frac{C_{\mathrm{A}}}{C_{\mathrm{K}}}$ is calculated by division of Eq. (2) by Eq. (1). The $C_{\mathrm{A}}$ and $C_{\mathrm{K}}$ can be estimated from the Eqs. (1) and (2) if at any height within the Two-Stream application range the $\beta_{\text {ref }}$ or $B(h)$ are known. The assumption that exactly the same air parcels are probed by both lidars during over-flights implies that only one representative profile of $\alpha(h)$ and $\beta(h)$ exists. Therefore the knowledge of any of the lidar instrumental constants allows for a direct calculation of the backscatter profile from Eqs. (1) or (2). Alternatively, the backscatter coefficient profiles can be derived from the Two-Stream approach by multiplying Eq. (1) by Eq. (2).

\section{Lidar instrumental constants}

Usually the lidar instrumental constant $C$ is not known precisely. For the standard elastic Klett-Fernald-Sasano and the inelastic Raman-Ansmann evaluation schemes it is redundant (height derivative of height independent variable). Any explicit calculations or measurements of $C$ are difficult and suffer from considerable error contributions, mainly due to the instabilities of the emitted laser energy, the transmission of the optical elements, and the detection efficiency (changes with applied voltage and surrounding temperature).

In our case, the lidar instrumental constants for the airborne $C_{\mathrm{A}}$ lidar and the ground based $C_{\mathrm{K}}$ lidar can be estimated directly from the Eqs. (1) and (2) if at any height within the Two-Stream application range additional information on the reference value $\beta_{\text {ref }}$ (e.g. known for aerosol free range in tropopause) or the lidar ratio $B(h)$ (e.g. known $B_{\mathrm{Ci}}$ for Cirrus clouds, as in this study) is available. When any of the two lidars sense the whole troposphere, and the particle optical depth $\tau_{\text {sun }}^{\text {part }}(\lambda)$ is known (performed nearby sun photometer measurement), the lidar constant of that system, e.g. $C_{\mathrm{K}}$ can be derived by rewriting the Eq. (1) to Eq. (5). However, Eq. (5) holds only for heights $h$ in the high troposphere or the stratosphere, were the particle extinction coefficient $\alpha^{\text {part }}$ can be neglected and the molecular extinction coefficient $\alpha^{\mathrm{mol}}$ can usually be assumed or obtained from nearby backscattering ratio radiosonde profiling.

$S_{\mathrm{K}}(h)=C_{\mathrm{K}} \beta(h) \exp \left(-2 \tau_{\text {sun }}^{\text {part }}\right) \exp \left(-2 \int_{0}^{h} \alpha^{\text {mol }} d z\right)$

By estimating $\beta(h)$ by $\beta^{\mathrm{mol}}(h)$ derived from the density and temperature profiles measured by the radiosonde, the $C_{\mathrm{K}}$ can be obtained as the mean value over all height increments $i$ in the high troposphere or the stratosphere (Eq. 6).

$C_{\mathrm{K}}=\left\langle\frac{S_{\mathrm{K}}(i)}{\beta(i) \exp \left(-2 \tau_{\mathrm{sun}}^{\mathrm{part}}\right) \exp \left(-2 \int_{0}^{i} \alpha^{\mathrm{mol}} d z\right)}\right\rangle_{i}$

For the purpose of this particular study the $C_{\mathrm{K}}$ was estimated separately for each of the analysed days. It was estimated in the aerosol-free range of the Arctic stratosphere between $10-12 \mathrm{~km}$ (where $\beta(h) \approx \beta^{\mathrm{mol}}(h)$ ) by using a standard KlettFernals-Sasano elastic inversion of the KARL's data with the following constrains:

- $\tau_{\mathrm{KFS}}^{\text {part }}$ obtained from Klett-Fernals-Sasano particle extinction profile in the whole range where it was applied, must be within $10 \%$ of the sun photometer value $\tau_{\text {sun }}^{\text {part }}$.

Note: Measurements were taken in the Arctic stratosphere, where the range corrected lidar signals normally follow the density profile measured by a colocated radiosonde very accurately. The stratospheric particle extinction can be neglected and the Eq. (5) holds true if the particle extinction in the lidar signal is expressed by the sun photometer's particle optical depth measured nearby (for this reason we constrain $\tau_{\mathrm{KFS}}^{\text {part }}$ with $\tau_{\mathrm{sun}}^{\text {part }}$ ). If so, knowledge of $\beta\left[0, h_{\mathrm{ov}}\right]$ and $\alpha\left[0, h_{\mathrm{ov}}\right]$ in the overlap region ( $h_{\mathrm{ov}}$ denotes the overlap height) does not influence the determination of $C_{\mathrm{K}}$ from the Eq. (5) because we express the integral from zero to $h_{\text {ref }}$ in stratosphere by $\tau_{\text {sun }}^{\text {part }}$ and we do not depend on the altitude where the extinction takes place. For this kind of lidar calibration our polar site conditions are more favorable compared to a heavily polluted low latitude site. The knowledge of a reasonably chosen $\beta(h)$ will practically limit the precision for the retrieval of the lidar constant.

- $\tau_{\mathrm{KFS}}^{\text {part }}$ obtained from Klett-Fernals-Sasano particle extinction profile in the range corresponding to the range where the Two-Stream was applied should match to the $\tau_{\mathrm{TS}}^{\text {part }}$ obtained from the Two-Stream $\alpha_{\mathrm{TS}}^{\text {part }}$ better than $5 \%$.

Note: We need to estimate $C_{\mathrm{K}}$ to make the backscatter coefficient profile calculated with the Two-Stream technique independent from the backscatter coefficient profile calculated by the Raman technique. We estimate this lidar constant and its uncertainty from the elastic lidar equation with several Klett solutions, which match to all avaliable information. In the range of altitudes where the Two-Stream is applicable we know the extinction coefficient profile but the lidar ratio in this range depends on $\beta_{\mathrm{KFS}}^{\mathrm{part}}$, which in turn depends on the assumptions above that Two-Stream region.

- altitudes where Cirrus or sub-visible clouds were detected by KARL at about $9 \mathrm{~km}$ were treated with a relatively low and uniform lidar ratio of $B_{\mathrm{Ci}}=12 \mathrm{sr}$, a 
value obtained by the transmittance method (Chen et al., 2002) applied to cases in this study.

Note: Cirrus clouds show a large spread in lidar ratios (Sassen and Comstock, 2001; Gayet et al., 2006; Immler et al., 2008) which are, among others, related to their temperature and altitude of occurrence, as these factors determine the form of the ice crystals in the cloud. Chen et al. (2002) used the transmittance method (explained therein) to derive $B_{\mathrm{Ci}}=29 \pm 12 \mathrm{sr}$ over Taiwan. Reichardt et al. (2002) reported values between $7 \mathrm{sr}$ and $30 \mathrm{sr}$ at $355 \mathrm{~nm}$ lidar wavelength for a subarctic site. The High Spectral Resolution Lidar measurements suggest a value around $28 \mathrm{sr}$ as being appropriate for Arctic Cirrus (Eloranta et al., 2006). For cases presented in this paper we used a lidar ratio of $12 \mathrm{sr}$ if Cirrus cloud appeared in the $532 \mathrm{~nm}$ signal. However, this number holds true only for the limited samples given here and not for all Cirrus clouds over Ny Ålesund.

- underestimated particle extinction from the ground to the KARL's completed overlap at a height $h_{\mathrm{ov}}$ was aproximated for all height steps as a constant value equal to the value of the particle extinction obtained with the Two-Stream at a height $h_{\mathrm{ov}}$ (i.e. $\alpha_{\mathrm{KFS}}^{\text {part }}(0: \Delta h$ : $\left.\left.h_{\mathrm{ov}}\right)=\alpha_{\mathrm{TS}}^{\mathrm{part}}\left(h_{\mathrm{ov}}\right)\right)$.

As the flight altitude does not necessarily take place in the aerosol free range it is difficult to estimate the reference backscatter value. A reasonably well chosen $\beta_{\text {ref }}$ can be given for the groundbased system in the lower stratosphere where the clear sky condition holds with good precision. If the KARL's $\beta_{\text {ref }}$ is fixed in the lower stratosphere, the value of the backscatter at the Two-Stream range depends on the lidar ratio above the aircraft. Hence, for our calculations an assumption on the lidar ratio was also made. Due to the fact that the Arctic atmosphere was relatively clear above the aircraft's flight altitude any reasonably chosen lidar ratio for the remaining altitudes $(10 \mathrm{sr}<B<50 \mathrm{sr})$ did not significantly alter the standard elastic Klett-Fernald-Sasano solution. Six different profiles were obtained for minimal, average and maximal values of the two quantities $\beta_{\text {ref }}$ and $B$ (each corresponding to a slightly different value of $C_{\mathrm{K}}$ ). The final value $C_{\mathrm{K}}$ used for the retrieval of the Two-Stream $\beta(h)$ was calculated as a mean averaged over all height positions $i$ in the reference range and over all of the different standard inversion solutions $j$ as in Eq. (7). From the scattering of $C_{\mathrm{K}}(j)$ around its mean value an uncertainty of $5 \%$ for the determination of the lidar constant was obtained.

$C_{\mathrm{K}}=\left\langle\left\langle\frac{S_{\mathrm{K}}(i)}{\beta(i) T_{[0, i]}^{2}}\right\rangle_{(i)}\right\rangle_{(j)}$

\section{Experimental results}

The applicability of the Two-Stream method depends critically on the constraint that both lidars probe into the same air masses. The best matching periods for the over-flights were found by correlating the measured signals using an a priori criterion (based on the input signals which do not depend on the results) for which profiles of both systems resembled in the bast way a common state in the atmosphere (Ritter et al., 2006). This was done by constructing a correlation map between both lidars' data sets corresponding to the time of the over-flight. In principal other methods might be feasible as well. For all data sets at times $t_{i}, t_{j}$ the correlation coefficient was calculated accordingly to Eq. (8) in which extinction cefficient was obtained with assumption of a constant lidar ratio ( $B=30 \mathrm{sr}$ ) using standard Klett-Fernald-Sasano inversion.

$$
\begin{aligned}
& \mathrm{CC}_{i, j}:= \operatorname{corr}\left\langle S_{\mathrm{A}}\left(h, t_{i}\right) \cdot \exp \left(+2 \int_{h_{\mathrm{ov}}^{\mathrm{K}}}^{h_{\mathrm{ov}}^{\mathrm{A}}} \alpha(h) d h\right),\right. \\
&\left.S_{\mathrm{K}}\left(h, t_{j}\right) \cdot \exp \left(-2 \int_{h_{\mathrm{ov}}^{\mathrm{K}}}^{h_{\mathrm{ov}}^{\mathrm{A}}} \alpha(h) d h\right)\right\rangle
\end{aligned}
$$

The $h_{\mathrm{ov}}^{\mathrm{K}}$ denotes the height beyond which the KARL's overlap is completed $(650 \mathrm{~m})$ and $h_{\mathrm{ov}}^{\mathrm{A}}$ denotes the height were the AMALi's overlap is completed $(235 \mathrm{~m})$.

The correlation coefficient was found a weak systematic function on position. The aircraft flew several legs (generally 3) over Ny Ålesund along coastline/fjord. There was always a fixed position in space where for the airborne system the correlation was maximal, with only weak time dependence to the groundbased system. For the limited data set at the coastal site the position was more important than the temporal evolution of the aerosol load. As our terrain was not homogeneous the best matching result for the TwoStream technique at the minimal distance between the footprints of the two lidars cannot be expected. An example of a correlation map can be found in Ritter et al. (2006). In the map's structure, places (and times) where the data sets between AMALi and KARL match each other better or worse were sistematically found. Hence, the correlation map and the comparability of the data show a physical sense and not just casual fluctuations.

The choice of $B$ influenced the values of the correlation coefficients but it did not have an effect on their relative minima and maxima. Moreover, if one lidar recorded clouds or aerosol layers at a different altitude to the other lidar (typical situation near the coastline) it was easily detected as a shift in the data sets (very low correlation in these cases). For all days under consideration the data sets heve been selected for evaluation at times that provided the absolute maximum of the correlation coefficient. As a result more range than required by constraints of each lidar's overlap was excluded for calculation (different air masses directly above the station and directly below the aircraft's flight path). 
Both data sets were averaged over $60 \mathrm{~m}$ in altitude. The shortest possible temporal averaging providing sufficient SNR (above 10 for a single $60 \mathrm{~m}$ range bin is required) was applied: $10 \mathrm{mn}$ for the ground based system and $8 \mathrm{mn}$ for the airborne lidar. The $\alpha_{\mathrm{TS}}(h)$ profiles were derived directly from Eq. (4) without any noise-treatment, as the extinction coefficient retrieval is methematically an ill-posed problem and even slight noise filtering can sevearly influence the inversion result (Pornsawad, 2008). Smoothing was applied only to already calculated $\alpha_{\mathrm{TS}}(h)$ by a running mean of $300 \mathrm{~m}$.

The Rayleigh extinction $\alpha^{\mathrm{mol}}(h)$ and backscatter $\beta^{\mathrm{mol}}(h)$ profiles due to the existence of molecules in the probed atmosphere were calculated from the temperature and pressure profiles measured by daily radiosonde launches at the Koldewey Station in Ny Ålesund. These were substracted (Rayleigh calibration) from the total $\alpha(h)$ and $\beta(h)$ profiles to obtain the particle $\alpha^{\text {part }}(h)$ and $\beta^{\text {part }}(h)$ profiles. The same substraction procedure was applied to the Two-Stream, the Raman, and the Klett-Fernald-Sasano approach.

The absorption contribution at $532 \mathrm{~nm}$ (mostly due to ozone) is negligible in the Arctic troposphere and thus was not considered in this analysis.

The particle optical depth calculated with the Two-Stream approach, i.e. $\tau_{\mathrm{TS}}^{\text {part }}$, was obtained by integration of the $\alpha_{\mathrm{TS}}^{\text {part }}$ profiles over the range interval avaliable for the Two-Stream application, which was estimated using the correlation algorithm applied prior to the evaluation (Eq. 8). Information on the particle optical depth of the whole atmosphere $\tau_{\text {sun }}^{\text {part }}$ at $532 \mathrm{~nm}$ was obtained from almost simultaneous measurements using the multi-channel spectrophotometer SP1A-14 (instrument described in Appendix C). The tropospheric particle optical depth $\tau_{\mathrm{KFS}}^{\text {part }}$ was integrated from $\alpha_{\mathrm{KFS}}^{\text {part }}$ over the avaliable range of the KARL's standard elastic Klett-FernaldSasano retrieval.

We used the inter comparisons of the particle optical depth obtained within the Two-Stream range $\tau_{\mathrm{TS}}^{\text {part }}$ (lower troposphere), the sun photometer's particle optical depth $\tau_{\text {sun }}^{\text {part }}$ (whole atmosphere), and the ground based lidar particle optical depth $\tau_{\mathrm{KFS}}^{\mathrm{p} \text { art }}$ (almost whole troposphere) for the determination of the lidar constant $C_{\mathrm{K}}$. Such comparisons are more appropriately applied to situations with as little as possible cloud contamination. As the sun photometer and the zenithpointing lidar were aimed at different directions in the Arctic atmosphere (low sun elevations) we cannot assume that there were time intervals where lidar and sun photometer simultaneously saw no cloud. Hence, a cloud screening was done for both instruments separately (in the case of the sun photometer the data with low particle optical depth $\tau_{\text {sun }}^{\text {part }}$ and high Ångström exponent $\AA$ were chosen). The comparison was done for the clearest time intervals, i.e. the lowest Cirrus contamination in the upper troposphere. In this case a $10 \%$ error of $\tau_{\text {sun }}^{\text {part }}=0.1$ gives rise to an error of approximately $2 \%$ in the aerosol extinction.
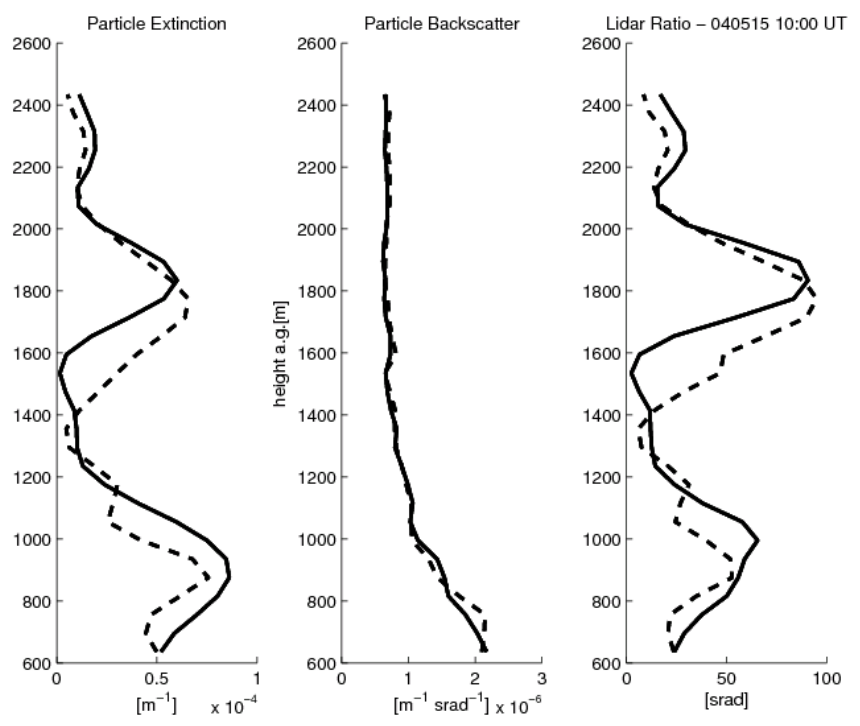

Fig. 1. The Two-Stream retrievals (solid) ploted with Raman (dashed) profiles for $532 \mathrm{~nm}$ on 15 May during the ASTAR 2004 campaign.

The ground based lidar instrumental constant $C_{\mathrm{K}}$ was estimated in the aerosol-free calibration range between 10 and $12 \mathrm{~km}$ with constraint on the best agreement of the $\tau_{\mathrm{KFS}}^{\text {part }}, \tau_{\mathrm{TS}}^{\text {part }}$ and $\tau_{\text {sun }}^{\text {part }}$. For 15 May 2004 the best agreement was obtained for a reference value $\beta_{\text {ref }}^{\text {part }}=0.03( \pm 0.05) \cdot \beta^{\text {mol }}$ (backscattering ratio $\left(\beta^{\mathrm{mol}}+\beta^{\text {part }}\right) / \beta^{\mathrm{mol}}=1.03$ ) resulting in a lidar constant $C_{\mathrm{K}}=1.65( \pm 0.1) \times 10^{14} \mathrm{mV} \mathrm{m}^{3}$ sr. For the same conditions on 19 May 2004 significantly higher value $C_{\mathrm{K}}=2.03( \pm 0.1) \times 10^{14} \mathrm{mV} \mathrm{m}^{3} \mathrm{sr}$ was obtained (due to implementation of a new flashlamp in the KARL's hardware and an increase of temperature in the laser room). For the data of 14 April 2005 the best agreement was obtained for $\beta_{\mathrm{ref}}^{\text {part }}=0.02( \pm 0.05) \cdot \beta^{\mathrm{mol}}$ (backscattering ratio of 1.02$)$ resulting in a lidar constant $C_{\mathrm{K}}=1.65( \pm 0.1) \times 10^{14} \mathrm{mV} \mathrm{m}^{3} \mathrm{sr}$.

With known $C_{\mathrm{K}}$ and $\alpha_{\mathrm{TS}}^{\mathrm{part}}(h)$ profiles we obtained $\beta_{\mathrm{TS}}^{\mathrm{part}}(h)$ profiles directly from Eq. (1) for each of the three days. The airborne lidar instrumental constant $C_{\mathrm{A}}$ was obtained from Eq. (2). The $C_{\mathrm{A}}=1.43( \pm 0.1) \times 10^{13} \mathrm{mV} \mathrm{m}^{3}$ sr was calculated on 15 May 2004 and 19 May 2004. On 14 April 2005 it was $C_{\mathrm{A}}=3.8( \pm 0.1) \times 10^{13} \mathrm{mV} \mathrm{m}^{3} \mathrm{sr}$ (due to a setting of $50 \mathrm{~V}$ higher PMT voltage).

The Two-Stream $\alpha_{\mathrm{TS}}^{\mathrm{part}}(h), \beta_{\mathrm{TS}}^{\mathrm{part}}(h)$ and $B_{\mathrm{TS}}(h)$ profiles at $532 \mathrm{~nm}$ were compared to the respective profiles derived using a standard method for the Raman retrieval (Ansmann et al., 1990, 1992) applied to the KARL's signals measured over Ny Ålesund. The Raman $\alpha_{\mathrm{RM}}^{\text {part }}(h)$ profiles were derived from the inelastic scattering lidar equation for $607 \mathrm{~nm}$, and Raman $\beta_{\mathrm{RM}}^{\text {part }}(h)$ profiles were calculated from the ratio of $532 \mathrm{~nm}$ and $607 \mathrm{~nm}$ signals with the mentioned $\beta_{\text {ref }}^{\text {part }}$, for consistency. The Raman evaluation was performed with $20 \mathrm{mn}$ integrations in time to assure sufficient SNR and (similarly 

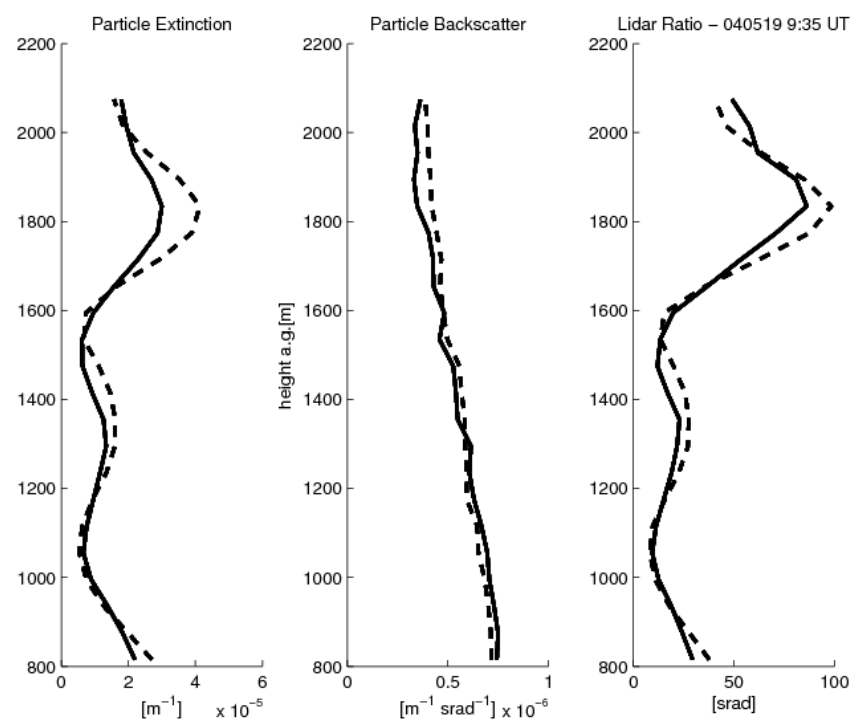

Fig. 2. The Two-Stream retrievals (solid) ploted with Raman (dashed) profiles for $532 \mathrm{~nm}$ on 19 May during the ASTAR 2004 campaign.

to the Two-Stream case) only retrieved $\alpha_{\mathrm{RM}}^{\text {part }}(h)$ profiles were smoothed by a running mean of $300 \mathrm{~m}$. The $10 \mathrm{mn}$ attenuated backscatter measurements used for the Two-Stream retrieval were centered within the $20 \mathrm{mn}$ Raman data acquisition sequence for 19 May 2004 and 14 April 2005. Due to the warm up of the KARL lidar a shifted mean (09:55-10:15) was used for the Raman evaluation on 15 May 2004 (Fig. 1), compared to a center of 10:00 for the Two-Stream. The best matching $20 \mathrm{mn}$ interval available for the Raman comparison was then applied. For the particle extinction retrieval with the Raman method the Ångström exponent Å was predefined. The Ångström exponent was derived from the sun and star photometer measurements over almost a decade at the observational site at Ny Ålesund, taking into account a broad variation depending on season and condition (e.g. occurrence of Arctic Haze, background aerosol, etc.) and gave on average $\AA=-1$ for May (Herber et al., 2002). As the subvisible Cirrus were frequently detected in the lidar profiles at high altitudes at this site a slightly lower value $\AA=-1.2$ was chosen for all Raman retrievals discussed in this paper. This assumption results in the error of the retrieved Raman particle extinction being less than $2 \%$. However, this error might be larger in the ranges directly below/in an inversion layer where the size, shape and possibly even the chemical composition of the scattering particles may drastically change with altitude. The Two-Stream approach is free of this error source as it directly utilises two elastic signals and therefore the Two-Stream extinction profile is retrieved independently of the choice of the Ångström exponent.

The Two-Stream profiles (solid lines) and the Raman profiles (dashed lines) for three days under consideration are presented in Figs. 1, 2 and 3.
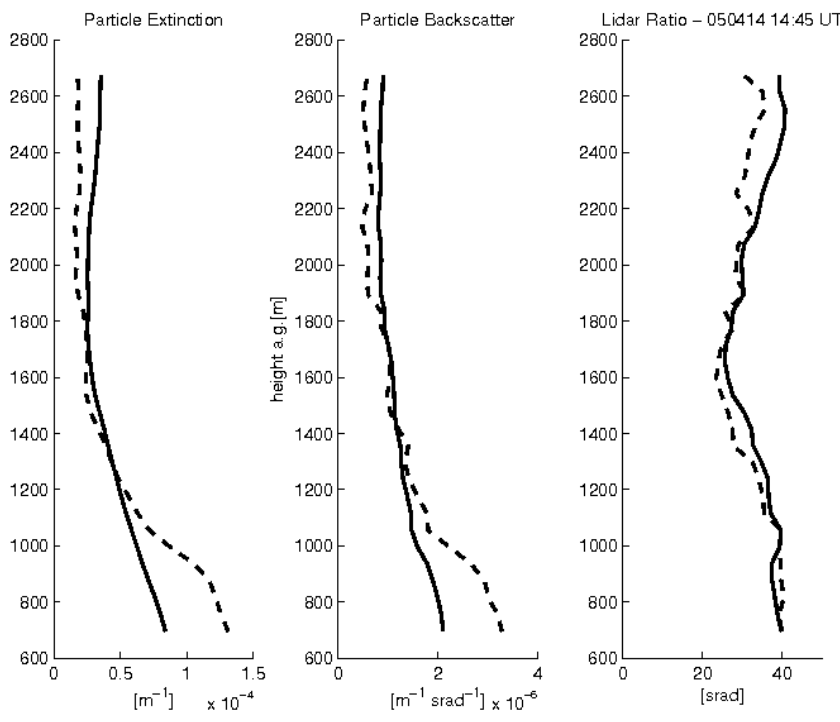

Fig. 3. The Two-Stream retrievals (solid) ploted with Raman (dashed) profiles for $532 \mathrm{~nm}$ on 14 April during the SvalEx 2005 campaign.

For 15 May 2004 (Fig. 1) the Two-Stream method was applied to data recorded around 10:00 UT at a height interval between 635 and $2435 \mathrm{~m}$. Two aerosol layers of strongly enhanced particle extinction and lidar ratio, indiscernible in the particle backscatter, are clearly visible in the Two-Stream as well as in the Raman retrievals. The upper layer has a maximum at $1800 \mathrm{~m}$ in the Two-Stream $\alpha_{\mathrm{TS}}^{\text {part }}(h)$ profile, while in the Raman $\alpha_{\mathrm{RM}}^{\mathrm{part}}(h)$ profile this maximum is $100 \mathrm{~m}$ lower. The lower layer has a maximum at around $900 \mathrm{~m}$ for both retrievals with higher particle extinction values in the TwoStream profile. The particle optical depth calculated from the Two-Stream interval $\tau_{\mathrm{TS}}^{\text {part }}$ sums up to 0.064 , mainly due to contribution from the mentioned layers. The sun photometer particle optical depth $\tau_{\text {sun }}^{\text {part }}$ measured at 10:00 UT in $\mathrm{Ny}$ Ålesund was 0.095 for $532 \mathrm{~nm}$. The radiosonde ascent at 11:00 UT in Ny Ålesund confirmed the existence of two layers. One at the altitude of $1200 \mathrm{~m}$ was characterised by the temperature gradient of $\Delta T_{\mathrm{inv}}=0.014{ }^{\circ} \mathrm{C} \mathrm{m}^{-1}$ and the humidity gradient of $\Delta \mathrm{RH}_{\mathrm{inv}}=0.264 \% \mathrm{~m}^{-1}$ ). The second layer was found at $1800 \mathrm{~m}$ with $\Delta T_{\text {inv }}=0.01{ }^{\circ} \mathrm{C} \mathrm{m}^{-1}$ and $\Delta \mathrm{RH}_{\mathrm{inv}}=0.525 \% \mathrm{~m}^{-1}$. During this measurement AMALi and KARL recorded volume depolarisation below 5\% at $532 \mathrm{~nm}$. The calculations of backward trajectories performed with the NOAA Hysplit Model (Draxler and Rolph, 2003) suggest, that the air remained isolated in the Arctic for at least six days. Apart from these two humid layers the air was very clean with particle extinction background values around $1.5 \times 10^{-5} \mathrm{~m}^{-1}$ and a lidar ratio around $20 \mathrm{sr}$. These values are characteristic for the clean Arctic air (Stachlewska, 2006a; Hofmann et al., 2009).

The data from around 09:35 UT on 19 May 2004 were analysed within a height interval of 815 and $2075 \mathrm{~m}$ (Fig. 2). The obtained retrievals coincided well displaying only small 
deviations at around $1800 \mathrm{~m}$. Here again a layer of enhanced particle extinction and lidar ratio around $80 \mathrm{sr}$ is visible. On this day even lower values of the particle backscatter were observed. Apart from the layer, the air appears clean, similarly to the previous day. The $\tau_{\mathrm{TS}}^{\text {part }}$ was 0.02 and measured at 10:00 UT on that day $\tau_{\text {sun }}^{\text {part }}$ was 0.11 for $532 \mathrm{~nm}$. The rediosonde released at 11:00 UT recorded a layer at $1800 \mathrm{~m}$ with $\Delta T_{\text {inv }}=0.012^{\circ} \mathrm{Cm}^{-1}$ and $\Delta \mathrm{RH}_{\mathrm{inv}}=0.14 \% \mathrm{~m}^{-1}$. Both lidars again measured very low volume depolarisation at $532 \mathrm{~nm}$. According to backward trajectories, the air streaked the coastline of north-western Sibiria three days prior to its arrival in Ny Ålesund.

On 14 April 2005 at around 14:45 UT (Fig. 3) the height interval between 660 and $2640 \mathrm{~m}$ shows strongly enhanced $\beta^{\text {part }}(h), \alpha^{\text {part }}(h)$ and $B(h)$ profiles (if compered with both previous days). The lowest values of the particle extinction are around $0.3 \times 10^{-4} \mathrm{~m}^{-1}$ corresponding to the maximum of the measured values on 19 May 2004. Likewise, the values of the backscatter are much higher than previously varying between $1-2.2 \times 10^{-6} \mathrm{~m}^{-1} \mathrm{sr}^{-1}$. The lidar ratio varies around 34 sr sugesting slightly polluted Arctic atmosphere. The $\tau_{\mathrm{TS}}^{\text {part }}$ sums up to 0.076 and the sun photometer measurement at 14:45 UT recorded $\tau_{\text {sun }}^{\text {part }}$ of 0.084 for $532 \mathrm{~nm}$. At the time corresponding to the evaluation there was no evidence of Cirrus or sub-visible clouds in the upper troposphere in the KARL's signals. Neither KARL nor AMALi recorded significant depolarisation signature at $532 \mathrm{~nm}$. The radiosonde ascent at 12:30 UT showed a very weak inversion layer at $700 \mathrm{~m}$ with $\Delta T_{\text {inv }}=0.005^{\circ} \mathrm{C} \mathrm{m}^{-1}$ and $\Delta \mathrm{RH}_{\text {inv }}=0.066 \% \mathrm{~m}^{-1}$, and no evidence of other layers up to the tropopause. The decrease in temperature and relative humidity droping from $50 \%$ at $700 \mathrm{~m}$ to its minimum of $22 \%$ at about $2000 \mathrm{~m}$ and rising again to reach $28 \%$ at $2500 \mathrm{~m}$, showed similarities with the particle extinction profile. The backward trajectories indicated uniform transport straight form the industrial part of Siberia, a typical precursor for an Arctic Haze event.

\subsection{Error analysis}

The error analysis for the Two-Stream $\alpha_{\mathrm{TS}}^{\text {part }}(h)$ and $\beta_{\mathrm{TS}}^{\text {part }}(h)$ profiles were performed according to error propagation. The SNR was determined for each lidar signal $P(h)$ with consideration of a height independent electronic noise $\mu$ and a photon noise for the calculation of a height dependent error $E(h)=\lambda \sqrt{P}(h)+\mu$. The electronic noise $\mu$ was estimated out of the background corrected raw data at the range where no laser light influenced the signals, i.e. for KARL at an altitude interval between 60 and $120 \mathrm{~km}$, and for AMALi in a pretrigger range of $400 \mathrm{~m}$ width.

Useful procedures for estimating $\lambda$ are described in Liu et al. (2006). In the data presented here the values for $\lambda$ were estimated from altitude intervals with constant aerosol load where variations in the lidar profiles on a scale of individual height increments were assumed to be caused purely by noise. For KARL this was in the lower stratosphere and
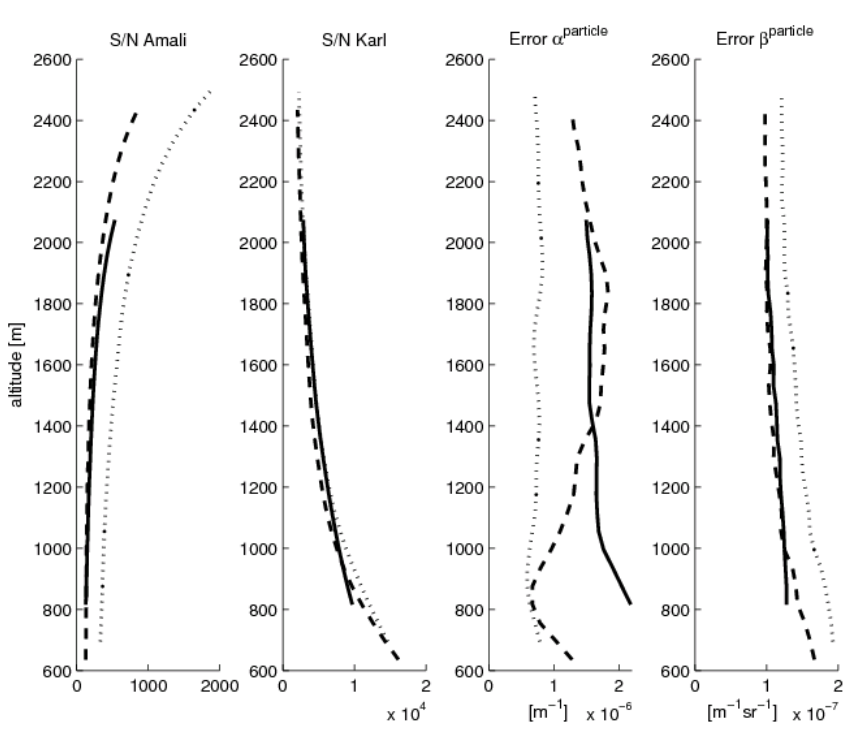

Fig. 4. The signal to noise ratio of AMALi and KARL lidars' raw data with the Two-Stream particle extinction and backscatter error values for 15 May 2004 (dashed), 19 May 2004 (solid) and 14 April 2005 (dotted). Values refer to $10 \mathrm{mn}$ and $60 \mathrm{~m}$ averaging at $532 \mathrm{~nm}$.

for AMALi in the layers which showed the least height dependent particle contamination in the $\alpha_{\mathrm{TS}}^{\text {part }}(h)$ and $\beta_{\mathrm{TS}}^{\text {part }}(h)$ profiles. This caused an overestimation of the noise in the airborne lidar signals when the variability of aerosol in the chosen range interval was present and, hence, a lower limit of the SNR of the airborne lidar was considered.

The molecular extinction and backscatter coefficients $\alpha^{\mathrm{mol}}(h)$ and $\beta^{\mathrm{mol}}(h)$ necessary for the Rayleigh calibration were calculated from radiosondes profiling. The error in the air density was estimated to be at most $2 \%$ for the time difference within two hours with respect to the Two-Stream calculation time. With this assumption approximatlely $10 \%$ of the errors in the particle extinction and backscatter coefficients $\alpha^{\text {part }}(h)$ and $\beta^{\text {part }}(h)$ for both the Two-Stream and Raman approach are caused by possible air density fluctuations.

Errors caused by neglecting the absorbtion due to trace gases and multiple scattering were not concidered.

Figure 4 shows the result of the error analysis for the TwoStream cases, where the SNR at $532 \mathrm{~nm}$ channel for both lidars and the corresponding errors of the Two-Stream extinction $\Delta \alpha_{\mathrm{TS}}^{\text {part }}(h)$ and backscatter $\Delta \beta_{\mathrm{TS}}^{\text {part }}(h)$ are given. The higher SNR for the AMALi on 14 April 2005 was caused by higher PMT voltage for the aquisition on that day. The $\Delta \alpha_{\mathrm{TS}}^{\text {part }}(h)$ do not show pronounced height dependence. In the Two-Stream approach both lidar signals have an opposite gradient of the SNR, which is a clear advantage over evaluation schemes with only one lidar. For the investigated cases the error of the Two-Stream particle extinction is below $\Delta \alpha_{\mathrm{TS}}^{\text {part }}=2 \times 10^{-6} \mathrm{~m}^{-1}$. Figure 5 gives an estimation of SNR at KARL's $607 \mathrm{~nm} \mathrm{~N} \mathrm{~N}_{2}$ channel, and errors of the Raman retrieved extinction $\Delta \alpha_{\mathrm{RM}}^{\mathrm{part}}(h)$ and backscatter 

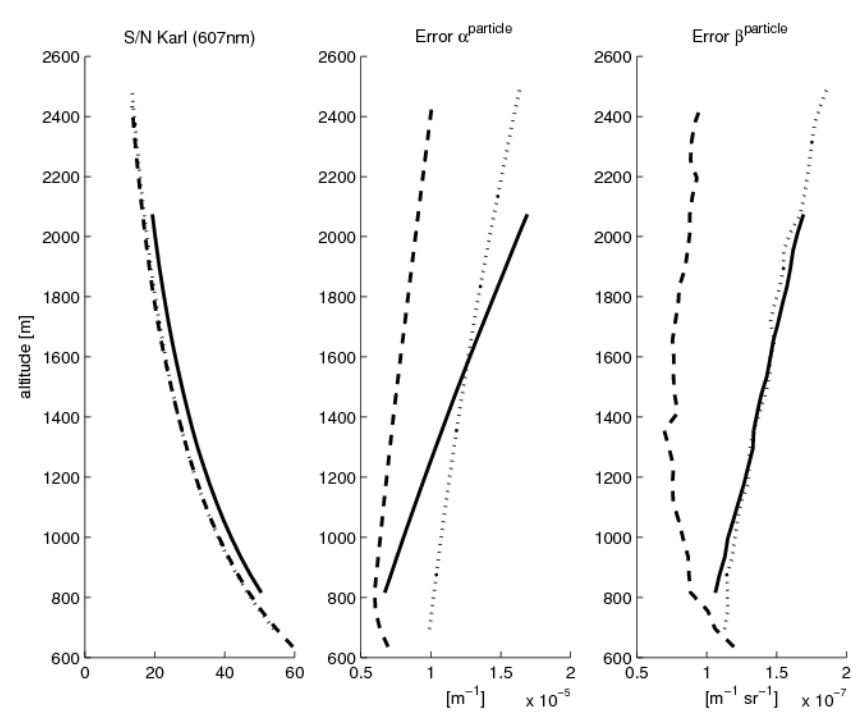

Fig. 5. The signal to noise ratio of the KARL's $607 \mathrm{~nm} \mathrm{~N} 2$ Raman channel at $20 \mathrm{mn}$ temporal and $60 \mathrm{~m}$ spatial averaging. The particle extinction and backscatter error values for 15 May 2004 (dashed), 19 May 2004 (solid) and 14 April 2005 (dotted) according to the standard Raman evaluation method.

$\Delta \beta_{\mathrm{RM}}^{\mathrm{part}}(h)$. As the SNR declines significantly with altitude the error increases accordingly. In the case of the data presented here, the error of the Raman particle extinction $\Delta \alpha_{\mathrm{RM}}^{\mathrm{p} \text { art }}$ is almost 10 times higher than the corresponding Two-Stream approach error $\Delta \alpha_{\mathrm{TS}}^{\text {part }}$.

The error of the Two-Stream backscatter $\Delta \beta_{\mathrm{TS}}^{\text {part }}(h)$ depends almost entirely on the error of the established lidar instrumental constants. According to applied constrains the $C_{\mathrm{K}}$ was obtained with $5 \%$ uncertainty which resulted in an accuracy of the backscatter coefficient below $\Delta \beta_{\mathrm{TS}}^{\text {part }}=$ $2 \times 10^{-7} \mathrm{~m}^{-1} \mathrm{sr}^{-1}$. Any possible errors in the determination of the extinction do not affect the backscatter retrieval. In contrary to the $\Delta \alpha_{\mathrm{TS}}^{\text {part }}(h)$, the $\Delta \beta_{\mathrm{TS}}^{\text {part }}(h)$ does not decrease with increasing signal strength. This is due to the fact that an uncertainty of the range corrected lidar signal $S$ is proportional to $\frac{\Delta S}{\sqrt{S}}$. As long as the error in the range corrected lidar signal $\Delta S$ is almost propotional to the root of the signal, there is no dependence on the error of $\Delta \beta_{\mathrm{TS}}^{\text {part }}(h)$. The error of the particle backscatter coefficient profiles obtained with in the Two-Stream and the Raman evaluation are similar for analysed data, as the boundary condition $\beta_{\text {ref }}$, necessary in both cases, determines this uncertainty.

A thorough error analysis is recommended when applying the Two-Stream method for another important reason. When two poorly matching lidar returns are divided by each other the Two-Stream algorithm can produce a physically unrealistic oscillation in the $\alpha_{\mathrm{TS}}^{\mathrm{p} \text { art }}(h)$ profile. With simple error analysis this problem can be easily addressed. If an amplitude of the mentioned artificial oscillations exceeds a value expected from the error analysis both employed lidar signals obviously do not contain the same atmospheric signal.

\section{Discussion}

For our calculations the assumption of negligible multiple scattering effect was made. For the AMALi (large beam divergence and field of view; see Appendix A; Stachlewska et al., 2004, 2009) the distance from lidar flight altitude to the ground was so short for a nadir-pointing configuration (less than $2.7 \mathrm{~km}$ ) that instrumental effect is negligible. Hence, only multiple scattering due to very dense aerosol load, thick clouds or fog would have had any impact. The multiple scattering effect calculated for the case of a mixed-phase cloud system (Stachlewska et al., 2006b; Gayet et al., 2007) using the multiple scattering model (Eloranta, 1998) showed that for such a relatively short distance the effect of multiple scattering is relevant only beyond the particle extinction threshold of $0.65 \times 10^{-3} \mathrm{~m}^{-1}$. In the profiles retrieved here the extinction was at least 2 orders of magnitude lower, and neglecting the multiple scattering for the AMALi observations was justified. For the KARL, neglecting the multiple scattering effect was justified by the instrument and measurement geometries (see Appendix B; Hofmann et al., 2009). The optical depth for midlevel clouds where the multiple scattering occurs is about 0.5 , far above the values considered in this study. Hence, it was decided that any influence of multiple scattering for the KARL could also be neglected.

The applicability of the Two-Stream method depends critically on the constraint that both lidars probe into the same air masses. This constraint was often not fulfilled at the Koldewey Station, where the KARL is installed. It is located near the coastline of Kongsfjord, an area rich in local meteorological phenomenon due to the cliffy orography of Svalbard. Additionally, due to their relative movement AMALi and KARL always detected different air masses directly above the station and below the aircraft. Hence, for the Two-Stream calculations more height steps were excluded than required only by a constraint on each lidars' overlap. The retrieval was strongly dependent on each lidars' SNR level. The data must be evaluated to obtain as high as possible SNR for as short as possible spatial and temporal averaging. In our case SNR of at least 10 for a single $60 \mathrm{~m}$ range bin was required (about $10 \mathrm{mn}$ integration time). The optimal configuration for the Two-Stream method employs two lidars with a similar SNR (as the particle extinction coefficient retrieval depends on both lidar signals equivalently). To find the most consistent data sets a correlation method was successfully applied.

The $\tau_{\text {sun }}^{\text {part }}$ obtained from almost simultaneous measurements with a sun photometer could only approximately be compared with the $\tau_{\mathrm{TS}}^{\text {part }}$ obtained from the Two-Stream particle extinction profiles, due to the short range of the latter retrieval. Care was also taken while comparing $\tau_{\text {sun }}^{\text {part }}$ with $\tau_{\mathrm{KFS}}^{\text {part }}$ obtained from the standard elastic Klett-Fernald-Sasano inversion applied to KARL's data. The zenith-pointing KARL generally probed different air to that of the sun photometer, which measured only at low elevations above the horizon (about $29^{\circ}$ at our polar site). In the direct comparison of 
the $\tau_{\mathrm{KFS}}^{\text {part }}$ with the $\tau_{\text {sun }}^{\text {part }}$ the latter value can only be used as basic information. Additionally, during both campaigns the KARL underestimated signals in the lowermost troposphere (high overlap), which resulted in the underestimation of the $\tau_{\mathrm{KFS}}^{\text {part }}$. Hence, the lidar constant $C_{\mathrm{K}}$, necessary to derive directly the Two-Stream $\beta_{\mathrm{TS}}^{\text {part }}(h)$, was obtained using mainly the constraint of the $\tau_{\mathrm{KFS}}^{\text {part }}$ matching the $\tau_{\mathrm{TS}}^{\text {part }}$. At lower latitudes more constraints could have been taken into account, so that an improvement in the retrieval for such cases can be expected.

The Two-Stream $\alpha_{\mathrm{TS}}^{\text {part }}(h), \beta_{\mathrm{TS}}^{\text {part }}(h)$ and $B_{\mathrm{TS}}(h)$ profiles derived from the $532 \mathrm{~nm}$ elastic signals of AMALi and KARL were compared with corresponding profiles derived for the KARL's Raman returns. The Raman evaluation was done with a minimum of $20 \mathrm{mn}$ integration time to assure sufficient SNR, while the Two-Stream retrievals were obtained with roughly $10 \mathrm{mn}$ averages. The error analysis showed, that the Raman $\alpha_{\mathrm{RM}}^{\text {part }}(h)$ retrievals are obtained with higher errors. Profiles obtained with both techniques (Figs. 1, 2, and 3) agree well, with the mentioned uncertainties (Figs. 4 and 5) and deviate only in the layers of high particle extinction values. While for 15 May 2004 one might speculate about a slight height shift between the profiles, such behaviour was not observed on other days. Therefore, we address these deviations to real variations of the atmosphere during the longer intergration of the Raman-shifted lidar profiles.

For both ASTAR 2004 days lidars recorded mainly clear air with the background particle extinction coefficient around $1.5 \times 10^{-5} \mathrm{~m}^{-1}$ and the lidar ratio of $20 \mathrm{sr}$, which are values characteristic of the clean arctic summertime conditions. Generally during ASTAR 2004 campaign extremely low contaminations were observed (Engvall et al., 2008). The $\tau_{\text {sun }}^{\text {part }}$ averaged for the whole campaign was around 0.08 for the $532 \mathrm{~nm}$, which must be at least partially addressed to the existence of Cirrus and sub-visible clouds in the upper troposphere. With both methods we obtained humid layers, which can be characterised by enhanced $\alpha^{\text {part }}(h)$ values, hardly visible in the $\beta^{\text {part }}(h)$ profiles. This once again underlines the necessity to determine backscatter and extinction independently of each other from the lidar measurements. The layers retrieved on both days at an altitude of about $1800 \mathrm{~m}$ (Figs. 1 and 2) matched the inversion layers measured by the radiosonde. Although the radiosonde launches took place up to two hours after the over-flights, we assume that the inversion layers could not change significantly during this time period as there were prolonged stable weather conditions on these days (Dörnbrack et al., 2010).

The enhanced relative humidity indicates existence of more wet particles in the layers than outside of it. The temperature below $-8^{\circ} \mathrm{C}$ suggests supercooled conditions rather than ice formation, which is supported by the low depolarization ratios indicating spherical particles. The calculations of backward trajectories give no evidence of possible anthro- pogenic pollution, which could contain absorbing particles. If the layers were dominated by spherical particles which are comparable or much larger than the interacting wavelength size $(532 \mathrm{~nm})$ it should show as an enhancement in both extinction and backscatter profile. We hypothesize that only an increased number of rather small spherical particles (effective radius of about $200 \mathrm{~nm}$ ) could give an enhanced particle extinction accompanied by a small particle backscatter and large lidar ratios, as seen in the layers at $900 \mathrm{~m}$ and $1800 \mathrm{~m}$ in Fig. 1 and at $1800 \mathrm{~m}$ in Fig. 2. Accordingly to Garrett et al. (2004) the smallest measured droplet sizes are much larger than $500 \mathrm{~nm}$, so this study illustrates particles rather than droplets. We argue that these layers were mainly composed of very small spherical supercooled water particles, not unusual in the pristine conditions of the Arctic region (Pinto et al., 2001; Treffeisen at al., 2007). However, heaving no in-situ measurements within, or outside these layers makes it difficult to discriminate between water and non absorbing cloud activated aerosol, which might consist of a sulfate core with a water shell (similar index of refraction). Hence, the high lidar ratios reported here may also indicate the existence of submicron aerosol particles activated in the humid environment.

Backward trajectories for 15 May 2004 suggest that the air under consideration remained isolated in the Arctic for at least six days and no anthropogenic pollutants could have been mixed into these layers. The backward trajectories of 19 May 2004 show the air mass passing briefly through non-Polar Regions as the air streaked the coastline of northwestern Europe and Sibiria three days prior to its arrival in Ny Ålesund. Due to the low extinction of this air, significant particle loads could not have been taken up and no anthropogenic pollutants were mixed into it. Therefore, a local origin of such humid layers over the Koldewey Station seems more likely than an advection phenomenon. Nearby mountains with an altitude of around $1 \mathrm{~km}$ cause local meteorological disturbances at the site, which seemed to be a source for formation of these layers (Dörnbrack et al., 2010) .

On 14 April 2005 a very local source of contaminations with $\mathrm{CO}, \mathrm{NO}_{2}$ and $\mathrm{SO}_{2}$ from the coal mining village in Barentsburg on Svalbard was possible. However, the backward trajectories indicate a uniform long-range transport over the mid-continental area of Yenisey and Lena Delta where soot particles could be expected in the anthropogenically contaminated air. This, together with the enhanced values of particle extinction and backscatter coefficients accompanied by the slowly varying vertical lidar ratio around $34 \mathrm{sr}$ (significantly higher than values typical for clean Arctic air of around $20 \mathrm{sr}$ ), the low humidity of $25-35 \%$, and the low volume depolarisation (below 10\%) indicate the occurrence of a weak Arctic Haze event rether than a local contaminations.

The difference of about $50 \%$ between the Two-Stream and Raman retrievals of the extinction and backscatter profiles observed below about $1 \mathrm{~km}$ in Fig. 3 on 14 April 2005 could not be caused by an overlap misalignment of the KARL, as 
it displayed more scattering. Neither was it a multiple scattering effect in the AMALi signal because the observed optical depth was too low for multiple scattering to set in, and backscatter and extinction were affected in the same way. Both methods retrieve a lidar ratio close to $40 \mathrm{sr}$ below $1 \mathrm{~km}$, which is close to the value for Arctic Haze measured at our high latitude station (Ritter et al., 2004); a value lower than the one found for Arctic Haze at lower latitudes (Müller et al., 2007). Altitudes below $1 \mathrm{~km}$ in Ny Ålesund are generally in a regime directly influenced by the local topography (e.g. in this study the radiosonde launched at 11:00 UT recorded a pronounced temperature inversion around $0.93 \mathrm{~km}$ altitude). Hence, it seems that below $1 \mathrm{~km}$ more local and more variable conditions were probed by the lidars whereas above $1 \mathrm{~km}$ the conditions were more stable. In both regimes the lidar ratio was however similar.

\section{Conclusions}

The Two-Stream method is an interesting evaluation tool for combined lidar observations. By means of the Two-Stream algorithm, (i) the two un-calibrated backscatter lidar signals, (ii) the reference backscatter coefficient value at any arbitrary altitude and (iii) the profiles of the molecular extinction and backscatter characterising the Rayleigh atmosphere are enough to retrieve the particle extinction and backscatter coefficient profiles and lidar ratio profile without ambiguity. Unlike for the standard elastic Klett-Fernals-Sasano inversion algorithm, which affects the gradient of the backscatter profile with incorrectly chosen lidar ratio $B(h)$ and value of the scattering at the reference altitude $\beta_{\text {ref }}$, for the TwoStream the choise of the $\beta_{\text {ref }}$ causes only a bias on the retrieved backscatter profile. If the $\beta_{\text {ref }}$ is not avaliable, the $\beta_{\mathrm{TS}}(h)$ solution can be obtained directly from the lidar equation if at least one of the lidar instrumental constants $C$ is estimated in any aerosol-free range.

The Two-Stream method was successful in the inversion of the AMALi and the KARL data at our polar site. The extinction coefficients were retrieved more accurately than with the Raman technique. Acurate retrievals were obtained for both clear and polluted atmospheric conditions. However, in unstable meteorological conditions, the critical constrain was the demand that both instruments probe the very same air to avoid artificial and meaningless extinction values. In profiles retrieved with the Two-Stream and the Raman techniques layers of enhanced values in $\alpha^{\text {part }}(h)$ profiles, indiscernible in the $\beta^{\text {part }}(h)$ profiles, but corresponding to very high $B(h)$ were found in the two cases of the ASTAR campaign. We interpreted them as layers of small spherical wet particles, of a non-antropogenic and local topography related origin. During the SvalEx campaign case such layers did not appear. Here strongly enhanced profiles of $\alpha^{\text {part }}(h)$ and $\beta^{\text {part }}(h)$ accompanied by an almost constant and high value of $B(h)$ were interpred as a weak Arctic Haze event of long range advection of aged small particles of antropogenic origin from lower latitudes.

The fact that one of the involved instruments in the TwoStream method must be air/space borne and eye-safe makes this approach quite expensive to be used on a everyday basis. However, during ASTAR 2007 ample application of this technique to the airborne lidar, ground based lidar and space borne lidar data, especially for the investigations of the late winter's Arctic Haze conditions, was made. For application of the Two-Stream approach to combined ground based lidar and satellite lidar measurements the evaluation scheme would have more factors to concern. For example frequency and time of the satellite overpasses, obtaining sufficient SNR, multiple scattering effect due to clouds and far range of satellite lidar would need to be considered. However, for the Two-Stream comparison it would be viable to utilise it on a quasi-homogeneous terrain with as little topographical influence as possible to allow more averaging for satellite lidar (e.g. from an aircraft flying over a free ocean along the satellite path). An experiment dedicated to the Two-Stream validation and analysis of the CALIPSO nadir-pointing lidar, frequently overflying the Arctic regions including vicinity of the Koldeway Station, was already performed during various AWI campaigns (e.g. ASTAR 2007) were a zenithpointing ground based KARL lidar and a zenith-pointing airborne AMALi lidar were used. In the future we plan to work on these data sets.

\section{Appendix A}

\section{The Airborne Mobile Aerosol Lidar (AMALi)}

The Airborne Mobile Aerosol Lidar (AMALi) developed at AWI is a small portable backscatter lidar designed for remote, simultaneous, high resolution detection of vertical and temporal extent of tropospheric aerosol load and depolarization (Stachlewska et al., 2004, 2009). In this study the version of the AMALi based on the Nd:Yag laser operating with $15 \mathrm{~Hz}$ repetition rate at $1064 \mathrm{~nm}$ and $532 \mathrm{~nm}$ with pulse energy of $60 \mathrm{~mJ}$ and $120 \mathrm{~mJ}$, respectively was used. As a reciever a $10.2 \mathrm{~cm}$ parabolic off-axis mirror with FOV of $3.1 \mathrm{mrad}$ was employed. The eye-safety at distances greater than $2.5 \mathrm{~km}$ off the system was assured by using a large laser beam divergence of $2.6 \mathrm{mrad}$. The nadir-pointing airborne measurements were limited to the near range by the eyesafety constrains and the maximum flight altitude of $3 \mathrm{~km}$ for the installation onboard a Dornier Do 288 aircraft (the AWI Polar 2 aircraft). Length of retrieved profiles varied between 2.5-2.7 km depending on flight altitude and taking into account $235 \mathrm{~m}$ losses due to overlap. This limitation allowed neglecting the multiple scattering effect due to large FOV and large laser beam divergence. For the Two-Stream calculations discussed in this paper the $532 \mathrm{~nm}$ signals averaged over $8 \mathrm{mn}$ with $60 \mathrm{~m}$ range resolution for $90 \mathrm{kt}$ aircraft's speed over ground were used. 


\section{Appendix B}

\section{The Koldewey Aerosol Raman Lidar (KARL)}

The developed at AWI Koldewey Aerosol Raman Lidar (KARL) is a ground based system integrated at the Koldewey Station in Ny Ålesund, Spitsbergen $\left(78.9^{\circ} \mathrm{N}, 11.9^{\circ} \mathrm{E}\right)$ serving for detection of tropospheric aerosols and water vapour (Ritter et al., 2004, 2008). The version of the KARL used for this study employed the Nd:Yag laser operating with $30 \mathrm{~Hz}$ repetition rate at $355 \mathrm{~nm}, 532 \mathrm{~nm}$ and $1064 \mathrm{~nm}$, each with energy around $2 \mathrm{~W}$. The recieving system had two mirrors; $10.8 \mathrm{~cm}$ diameter with FOV of $2.25 \mathrm{mrad}$ for near range (from $650 \mathrm{~m}$ to $6 \mathrm{~km}$ ) and $30 \mathrm{~cm}$ diameter and FOV of $0.83 \mathrm{mrad}$ for far range (from $2 \mathrm{~km}$ to lower stratosphere) measurements. Detection was provided at the IR, VIS, UV elastic backscatter channels, VIS depolarisation, and Ramanshifted wavelengths for nitrogen at $387 \mathrm{~nm}$ and $607 \mathrm{~nm}$ and for water vapour at $407 \mathrm{~nm}$ and $660 \mathrm{~nm}$. For the application to the Two-Stream the $532 \mathrm{~nm}$ elastic data with standard averaging over $10 \mathrm{mn}$ and $60 \mathrm{~m}$ ranging from overlap up to $15 \mathrm{~km}$ were used. The inelastic signals at $607 \mathrm{~nm}$ were averaged over $20 \mathrm{mn}$ and $300 \mathrm{~m}$.

\section{Appendix C}

\section{The multi-channel spectrophotometer}

The multi-channel spectrophotometer SP1A-14 manufactured by Dr. Schulz \& Partner, Buckow, Germany has a measurement range covering UV, VIS and IR light spectrum, where 8 channels are selected accordingly to the WMO/1983 recommendation and VDI 3786/10/3 recommendation (368, $412,500,600,675,778,862,1024 \mathrm{~nm})$ and 10 are additional $(353,389,450,532,760,911,946,967,1045,1064 \mathrm{~nm})$. A full measuring cycle, i.e. collecting and storing the data of 18 channels and calling up the next cycle, is taken within $8 \mathrm{~s}$. Calibration is performed with artifical radiation sources at the optical laboratory using the Leiterer calibrating method (Leiterer et al., 1985) or during a field experiment using the Langley-extrapolation method (Shaw, 1983). The latter one must be performed in a case of cloud absence along the optical path and extremely low variations in the planetary boundary layer, which are often occuring during very clear air conditions in the Polar Regions. For this study we used the $532 \mathrm{~nm}$ channel for the particle optical depth comparisons.

Acknowledgements. The authors would like to thank the anonymous referees and Adrain Webb who helped us to improve this manuscript with their valuable comments and contributions. We acknowledge the NOAA Air Resources Laboratory (ARL) for the provision of the HYSPLIT transport and dispersion model used in this publication.

Edited by: A. Minikin

\section{References}

Ackermann, J.: The extinction to backscatter ratio of tropospheric aerosol: A numerical study, J. Atmos. Ocean. Technol., 15, 1043-1050, 1998.

Ansmann, A., Riebesell, M., and Weitkamp, C.: Measurements of aerosol profiles with Raman lidar, Opt. Lett., 15, 746-748, 1990.

Ansmann, A., Wandinger, U., Riebesell, M., Weitkamp, C., and Michaelis, W.: Independent measurements of extinction and backscatter profiles in Cirrus clouds by using a combined Raman elastic-backscatter Lidar, Appl. Optics, 31, 7113-7131, 1992.

Böckmann, C.: Hybrid regularisation method for ill-posed inversion of multiwavelength lidar data in the retrieval of aerosol size distribution, Appl. Optics, 40, 1329-1341, 2001.

Böckmann, C. and Kirsche, A.: Iterative regularization method for lidar remote sensing, Comput. Phys. Commun., 174(8), 607615, 2006.

Chen, W., Chiang, C., and Nee, J.: Lidar Ratio and Depolarization Ratio for Cirrus Clouds, Appl. Optics, 41, 6470-6476, 2002.

Cuesta, J. and Flamant, P. H.: Two-Stream lidar inversion algorithm for airborne and satellite validations, in: Proceedings of 22nd International Laser Radar Conference (IBC 2004), edited by: Pappalardo, G. and Amodeo, A., ESA SP-561, 1, 471-474, 2004.

Dörnbrack, A., Stachlewska, I. S., Ritter, C., and Neuber, R.: Aerosol distribution around Svalbard during intense easterly winds, Atmos. Chem. Phys., 10, 1473-1490, 2010, http://www.atmos-chem-phys.net/10/1473/2010/.

Draxler, R. R. and Rolph, G. D.: HYSPLIT (HYbrid Single-Particle Lagrangian Integrated Trajectory) Model, Real-time Environmental Applications and Display sYstem (READY) Website http://www.arl.noaa.gov/ready/hysplit4.html, NOAA Air Resources Laboratory, Silver Spring, MD, 2003.

Eloranta, E. W.: Practical Model for the Calculation of Multiply Scattered Lidar Returns, Appl. Optics, 37, 2464-2472, 1998.

Eloranta, E. W. , Razenkov, I. A., and Garcia, J. P.: Arctic Observations with the University of Wisconsin High Spectral Resolution Lidar, in Reviewed and Revised Papers Presented at the 23rd International Laser Radar Conference, edited by: Nagasawa, C. and Sugimoto, N., pp. 399-402, 2006.

Engvall, A.-C., Krejci, R., Ström, J., Minikin, A., Treffeisen, R., Stohl, A., and Herber, A.: In-situ airborne observations of the microphysical properties of the Arctic tropospheric aerosol during late spring and summer, Tellus B, 60, 392-404, doi:10.1111/j.1600.0889.2008.00348.x, 2008.

Fernald, F. G.: Analysis of atmospheric lidar observations: some comments, Appl. Optics, 23, 652-653, 1984.

Gayet, J. F., Shcherbakov, V., Mannstein, H., Minikin, A., Schumann, U., Ström, J., Petzold, A., Ovarlez, J., and Immler, F.: Microphysical and optical properties of mid-latitude Cirrus Cloud observed in the southern hemisphere during INCA, Q. J. Roy. Meteorol. Soc., 132, 2791-2748, doi:10.1256/qj.05.162, 2006.

Gayet, J.-F., Stachlewska, I. S., Jourdan, O., Shcherbakov, V., Schwarzenboeck, A., and Neuber, R.: Microphysical and optical properties of precipitating drizzle and ice particles obtained from alternated lidar and in situ measurements, Ann. Geophys., 25, 1487-1497, 2007, http://www.ann-geophys.net/25/1487/2007/.

Garrett, T. J., Zhao, C., Dong, X., Mace, G. G., and Hobbs, P. V.: Effects of varying aerosol regimes on low-level Arctic stratus, Geophys. Res. Lett., 31, L17105, doi:10.1029/2004GL019928, 
2004.

Herber, A., Thomason, L. W., Gernandt, H., Leiterer, U., Nagel, D., Schulz, K.-H., Kaptur, J., Albrecht, T., and Notholt, J.: Continuous day and night aerosol optical depth observations in the Arctic between 1991 and 1999, J. Geophys. Res., 107(D10), 4097, doi:10.1029/2001JD000536, 2002.

Hughes, H. G. and Paulson, M. R.: Double-ended lidar techniques for aerosol studies, Appl. Optics, 27, 2273-2278, 1988.

Hoffmann, A., Ritter, C., Stock, M., Shiobara, M., Lampert, A., Maturilli, M., Orgis, T., Neuber, R., and Herber, A.: Ground-based lidar measurements from Ny-Ålesund during ASTAR 2007, Atmos. Chem. Phys., 9, 9059-9081, 2009,

http://www.atmos-chem-phys.net/9/9059/2009/.

Immler, F., Treffeisen, R., Engelbart, D., Krüger, K., and Schrems, O.: Cirrus, contrails, and ice supersaturated regions in high pressure systems at northern mid latitudes, Atmos. Chem. Phys., 8, 1689-1699, 2008,

http://www.atmos-chem-phys.net/8/1689/2008/.

Jörgensen, H. E., Mikkelsen, T., Streicher, J., Herrmann, H., Werner, C., and Lyck, E.: Lidar calibration experiments, Appl. Phys. B Lasers O., 64(3), 355-361, 1997.

Klett, J. D.: Stable analytical inversion solution for processing lidar returns, Appl. Optics, 20, 211-220, 1981.

Klett, J. D.: Lidar inversions with variable backscatter/extinction velues, Appl. Optics, 24, 211-220, 1985.

Kovalev, V. A. and Eichinger, W. E.: Elastic Lidar: Theory, Practice, and Analysis Methods, J. Wiley \& Sons, New York, ISBN 0-471-20171-5, 2004.

Kunz, G. J.: Bipath Method as a way to measure the spatial backscatter and extinction coefficients with lidar, Appl. Optics, 26, 794-795, 1987.

Leiterer, U., Weller, M., and Janiak, J.: Verfahren zur Bestrahlungsstärke- und Strahldichtekalibrierung von Spektrometern, Patentschrift DD 228631 A1, WP GO1 D/265 1067 v. 16.10., 1985.

Liu, Z., Hunt, W., Vaughan, M., Hostetler, C., McGill, M., Powell, $\mathrm{K}$. Winker, D., and Hu, Y.: Estimating random errors due to shot noise in backscatter lidar observations, Appl. Optics, 45, 44374447, 2006.

Müller, D., Wandinger, U., and Ansmann, A.: Microphysical particle parameters from extinction and backscatter data by inversion with regularization, Appl. Optics, 38, 2358-2368, 1999.

Müller, D., Ansmann, A., Mattis, I., Tesche, M., Wandinger, U., Althausen, D., and Pisani, G.: Aerosol-type-dependent lidar ratios observed with Raman lidar, J. Geophys. Res., 112, D16202, doi:10.1029/2006JD008292, 2007.

Pinto, J. O., Curry, J. A., and Intrieri, J. M.: Cloud-aerosol interactions during autumn over Beaufort Sea, J. Geophys. Res., 106(D14), 15077-15097, 2001.

Pornsawad, P., Böckmann, C., Ritter, C., and Rafler, M.: Ill-posed retrieval of aerosol extinction coefficient profiles from Raman lidar data by regularization, Appl. Optics, 47, 1649-1661, 2008.

Reichardt, J., Reichardt, S., Behrendt, A., and McGee, T. J.: Correlations among the optical properties of Cirrus-cloud particles: Implications for space borne remote sensing, Geophys. Res. Lett., 29(14), 1668, doi:10.1029/2002GL014836, 2002.

Ritter, C., Kirsche, A., and Neuber, R.: Tropospheric Aerosol Characterized by a Raman Lidar over Spitsbergen, in: Proceedings of 22nd International Laser Radar Conference (ILRC 2004 in Mat- era, Italy), edited by: Pappalardo, G. and Amodeo, A., ESA SP561, 1, 459-462, ISBN 92-9092-872-7, 2004.

Ritter, C., Stachlewska, I. S., and Neuber, R.: Application of the Two-Stream evaluation for a case study of Arctic Haze over Spitsbergen, in: Proceedings of 23nd International Laser Radar Conference (ILRC 2006 in Nara, Japan), edited by: Nagasawa, C. and Sugimoto, N., 1, 507-510, ISBN 4-9902916-0-3, 2006.

Ritter, C., Hoffmann, A., Osterloh, L., and Böckmann, C.: Estimation of the Liquid Water Content of a low-level Arctic winter cloud, in: Proceedings of 24nd International Laser Radar Conference (ILRC 2008 in Boulder, Colorado, USA), 1, 579-582, ISBN 978-0-615-21489-4, 2008.

Sasano, Y., Browell, E. V., and Ismail, S.: Error caused by using a constant extinction/backscattering ratio in the lidar solution, Appl. Optics, 24, 3929-3932, 1985.

Sassen, K. and Comstock, J. M.: A midlatitude Cirrus cloud climatology from the facility for atmospheric remote sensing. Part III: Radiative properties, J. Atmos. Sci., 58 , 2113-2127, 2001.

Shaw, G. E.: Sun Photometry, B. Am. Meteorol. Soc., 64, 4-10, 1983.

Stachlewska, I. S., Wehrle, G., Stein, B., and Neuber, R.: Airborne Mobile Aerosol Lidar for measurements of Arctic aerosols, in: Proceedings of 22nd International Laser Radar Conference (ILRC 2004), edited by: Pappalardo, G. and Amodeo, A., ESA SP-561, 1, 87-89, 2004.

Stachlewska, I. S., Ritter, C., and Neuber, R.: Application of the Two-Stream inversion algorithm for retrieval of extinction, backscatter and lidar ratio for clean and polluted Arctic air, in: Proceedings of SPIE, 5584, 03/1-03/8, 2005.

Stachlewska, I. S.: Investigation of tropospheric arctic aerosol and mixed-phase clouds using airborne lidar technique, $\mathrm{PhD}$ Thesis, University of Potsdam, http://opus.kobv.de/ubp/volltexte/2006/ 698/, 2006a.

Stachlewska, I. S., Gayet, J.-F., Duroure, C., Schwarzenboeck, A., Jourdan, O., Shcherbakov, V., and Neuber, R.: Observations of mixed-phase clouds using airborne lidar and in-situ instrumentation, in: Reviewed and Revised Papers Presented at the 23rd International Laser Radar Conference (ILRC 2006), 1, 325-328, 2006 b.

Stachlewska, I. S., Neuber, R., Lampert, A., Ritter, C., and Wehrle, G.: AMALi - the Airborne Mobile Aerosol Lidar for Arctic research, Atmos. Chem. Phys. Discuss., 9, 18745-18792, 2009, http://www.atmos-chem-phys-discuss.net/9/18745/2009/.

Treffeisen, R., Krejci, R., Ström, J., Engvall, A. C., Herber, A., and Thomason, L.: Humidity observations in the Arctic troposphere over Ny-Ålesund, Svalbard based on 15 years of radiosonde data, Atmos. Chem. Phys., 7, 2721-2732, 2007,

http://www.atmos-chem-phys.net/7/2721/2007/.

Veselovskii, I., Kologotin, A., Griazanow, V., Müller, D., and Whitemann, D.: Inversion with regularization for the retrieval of tropospheric aerosol parameters from multiwavelength lidar sounding, Appl. Optics, 18, 3685-3699, 2002.

Wang, X., Frontoso, M. G., Pisani, G., and Spinelli, N.: Retrieval of atmospheric particles optical properties by combining ground based and space borne lidar elastic scattering profiles, Opt. Express, 15, 6734-6743, 2007.

Winker, D. M., Hunt, B. H., and McGill, M. J.: Initial performance assessment of CALIOP, Geophys. Res. Lett., 34, L19803, doi:10.1029/2007GL030135, 2007. 